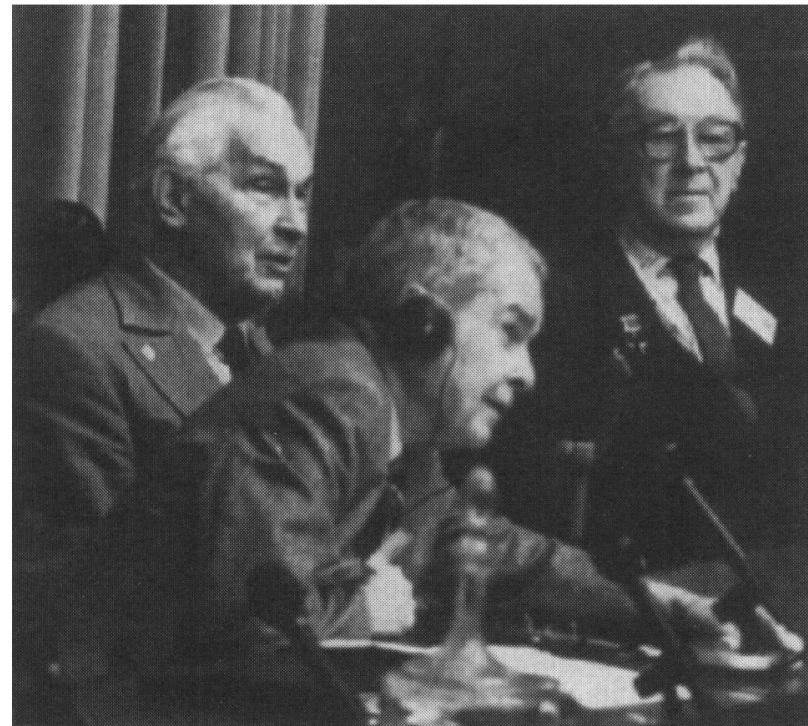

FIG. 2. A typical sharing of chairmanship (from left to right: Kovda Polunin, and Academician Aleksandr L. Yanshin).

Honorary Membership of the Indian Society of Soil Science, Honorary Membership of the Hungarian Soil Science Society, Foreign Membership of the Agricultural Academy of France, honorary doctorates of various Western European universities, and above all his presidency, from 1973 to 1976 , of the "environmental summit' of ICSU's SCOPE (which he always referred to as 'Scòpé'). In addition he was a Councillor of the World Council For The Biosphere from its inception in 1974 and the recipient of numerous awards, including no fewer than six USSR State ones (despite being seemingly apolitical). He also received the Order of Friendship of China, the Dokuchaev Gold Medal, the Silver Medal and Prize of the French Society of Soil Science, the UNESCO Prize for Science, ${ }^{*}$ and the Diploma of Honour on Irrigation and Drainage of the International Commission of the United Nations.

Author of more than 600 publications for the most part in Russian, Kovda was celebrated for some 30 of these

* In 1972, 'heading a group of nine Austrian Research Workers'. being monographs of more or less major dimensions including Solonchaks and Solonets (1937), The Origin and Regime of Saline Soils (two volumes, 1946 and 1947), Principles of Pedology (two volumes, 1973), Biogeochemistry of Soil Cover (1985), Problems of Protection of the Soil Cover and the Biosphere of the Planet (1989), and Governmental Ecological Policy (1991). In addition he was co-Author and Editor of the following maps: Soil Map of Iran (1941-45), Soil Map of China (1955, 1958), Soil Map of Asia $(1960,1971)$, and Soil Map of the World $(1965,1971)$.

From our environmentalists' viewpoint Victor Kovda was clearly a major figure - not merely in the vital field of soil science but above all in being perhaps the first farseeing biospherologist having full comprehension of the immense implications of our only human and indeed all life's home being The Biosphere. This realization prompted his original proposal with one of us (NP) of an International Centre for Biosphere Studies. Creation of this last was further recommended in the Declaration of the International Symposium 'Man and Biosphere: History and Modern Times', held during 20-25 March 1989 in Pushchino ( $c f$. Environmental Conservation, 16[3], pp. 280-2 with 3 figs, 1989), following which it was finally established as described by the other of us (VAD, Idem, 17[3], p. 273, 1990). Further outcomes of this realization have included Kovda's far-sighted proposal described in the second paragraph of this note, our own of Biosphere Day*, and the proposal of a Global Commons Trust Fund $\uparrow$. Fig. 2 shows a typical sharing of chairmanship.

VERA A. DMITRIEVA, Executive Director

Vernadsky International Centre for Biosphere Studies PO Box 156, Pushchino, Moscow Region, Russia, \&

Nicholas PoluniN

Editor of this Journal.

* Of which the latest published version is on page 194 of our current volume (Environmental Conservation, 19[3], p. 194, 1992); see also ibid. page 193 headed 'Biosphere Day and Its Needed Fund and Prizes' and our Foundation for Environmental Conservation's Promoting and Collating of Biosphere Clubs. - Ed.

$\dagger$ See the Guest Editorial 'A Proposal in Observation of Biosphere Day: Repairing The Biosphere Through a Global Commons Trust Fund', by Professor Christopher D. Stone (Idem, pp. 3-5).

\title{
Gratifying Recognition of a Colleague
}

$\mathrm{R}$ eal eminence of outstanding academics is rarely recognized publicly in the manner of even transitory performance on the stage or in sport, yet scholars are the ones whose products are apt to have major, even global, significance. So it is warmly gratifying to observe that one of our distinguished panel of Advisory Editors, our longtime friend and Harvard colleague Professor Richard Evans Schultes - who fortunately is not averse to personal publicity provided it is truthful and reasonably dignified has this year come in for widespread recognition in various ways of which the following three have been chosen for information to our readership:

1. The Linnean Gold Medal for 1992 , characterized by the President of the donor Linnean Society of London as 'this well-deserved honour'. Since its inception in 1888 this, one of science's most prestigious awards, has been bestowed on only 7 Americans, 5 of whom were Harvard Professors.

2. The Harvard Medal for 1992, the words of the President of Harvard University in bestowing the honour on our
Advisory Editor being: 'Unabashed by your love for Harvard, you are an inspirational teacher of botany and an international explorer who has sought to preserve not only the rain-forest, but also the cultures of those [humans] who live there. Your life's work has brought many honors to you and your Alma Mater.'

3. 'Jungle Botanist' - the title of a 24-pages-long 'Profile' in The New Yorker of 1 June 1992, opening with an excellent drawn likeness. Included are such observations as 'Schultes may be the only living person to have more than two million acres of the Earth named after him - Sector Schultes, an Amazonian tract thus formally designated in 1986 by the Colombian government.' So evidently due major-scale recognition can still come, whether the subject welcomes it or not, as we observe with special pleasure in this instance in which, even if public opinion does not recognize a discovery or scholarly advance, a national government may do so.

Nicholas PoluniN 